\title{
Habitat Preference and Population Structure of Two Data Deficient Seahorse (Syngnathidae) Species
}

\author{
N. Perera1, 2, D. D. G. L. Dahanayaka ${ }^{3}$ and \\ S. Udagedara ${ }^{1}$ \\ ${ }^{1}$ Blue Resources Trust, No.86, Barnes Place, Colombo 7, Sri Lanka \\ ${ }^{2}$ Department of Biology and Environmental Science, Linnaeus \\ University, 39182 Kalmar, Sweden \\ ${ }^{3}$ Department of Zoology, Faculty of Natural Sciences, The Open \\ University of Sri Lanka, Nawala, Sri Lanka
}

\section{Abstract}

Ecological studies of seahorses are sparse in the Indian Ocean. The vulnerability of seahorses to overfishing and increased anthropogenic impacts on coastal habitats necessitates better management of wild seahorse populations that in turn requires understanding habitat preferences and population structure. The distribution patterns and population structure of two species of seahorse (Hippocampus fuscus and $H$. spinosissimus) were assessed for the first time in a tropical estuary in north-western Sri Lanka. Both species have previously not been studied in the wild and have not been known to occur in estuaries.

$H$. fuscus was the more abundant and widely distributed species, and was significantly larger than $H$. spinosissimus. Both species had significant differences in size between sexes, and the mean height was towards the lower end of the range know for both species. Some sexually mature males were smaller than the size reported in the literature.

*Correspondence should be addressed to N. Perera Email: nishan@blueresources.org

https://orcid.org/0000-0001-7025-1399

(Received $12^{\text {th }}$ October 2017; Revised 24th November 2017; Accepted 28 th November 2017) C OUSL 
Seahorses occurred in low densities with patchy distribution, with abundance being higher in areas with the seagrass species Enhalus acoroides and Cymodocea serrulata that appear to be the favored habitat of seahorses within the study area.

Key words: distribution, habitat, lagoon, seagrass, seahorse, Sri Lanka

\section{Introduction}

Seahorses are marine fish belonging to the genus Hippocampus (family Syngnathidae), found in both temperate and tropical waters in the Atlantic and Indo-Pacific marine eco regions (Lourie et al., 2004). They inhabit a variety of habitats such as coral reefs, seagrass meadows, mangroves, estuaries and open bottom habitats, although their distribution can be patchy and sparse (Perante, 2002; Foster \& Vincen, 2004; Rosa et al., 2007). Seahorses are weak swimmers and tend to anchor themselves to vegetation or the substrate using a strong prehensile tail (Kendrick \& Hyndes, 2005), and rely on prey coming within close range instead of actively pursuing them (Foster and Vincent, 2004; Lourie et al., 2004; Felício et al., 2006). As a result, they are highly localized with small home ranges, and life history characteristics such as low fecundity, lengthy parental care, and mate fidelity make them particularly vulnerable to overexploitation (Foster \& Vincent, 2004).

Seahorses are harvested extensively for use in Traditional Chinese Medicine (TCM), as curios and for the marine aquarium trade (Vincent, 1995a; Vincent, 1995b;Vincent et al., 2011). In addition, large numbers of seahorses are caught as by-catch in commercial fisheries (Baum et al., 2003; Salin \& Yohannan, 2005; Giles et al., 2006) and many important seahorse habitats such as coral reefs and seagrass meadows are degraded or threatened by human activities (Wilkinson, 2000). As a result global seahorse populations are believed to have declined rapidly (Baum \& Vincent, 2005; Curtis and Vincent, 2008; Vincent et al., 2011). Thirty eight (38) species of seahorses have been listed on the IUCN Red List of Threatened Species (IUCN, 2010) and the entire genus Hippocampus has been added to Appendix II of the Convention on International Trade in Endangered Species of Wild Fauna and Flora (CITES) in order to monitor and regulate international trade (Martin-Smith \& Vincent, 2006). 
Listing seahorses on CITES Appendix II obliges signatory countries to determine sustainable levels of trade. Managing wild populations requires information on population status and extraction levels as well as the space use and ecology (Rosa et al., 2007). The Indo-Pacific region contains the highest diversity of marine fish including seahorses but also has the greatest threats to habitats and species (Allen, 2008) with welldocumented seahorse fisheries supplying both the TCM and aquarium trades (Giles et al., 2006; Meeuwig et al., 2006; O'Donnell et al., 2010; Perry et al., 2010). However, there are extensive gaps in the knowledge of seahorse distribution, ecology, and population status resulting in many seahorse species being listed as Data Deficient in the IUCN Red List of Threatened Species. In the Indian Ocean, information on seahorse fisheries and ecology is limited to a few studies in Africa and India (Bell et al., 2003; McPherson \& Vincent, 2004; Salin \& Yohannan, 2005; Vincent et al., 2011). More species-specific studies are encouraged due to the paucity of data on many seahorse species (Foster \& Vincent, 2004).

Sri Lanka is a major exporter of live seahorses for the marine aquarium trade (Wabnitz et al., 2003). However, information related to seahorse species, distribution, ecology and fisheries is sparse. Reviews of the marine aquarium trade in Sri Lanka (Ekaratne, 2000; Wijesekara \& Yakupitiyage, 2001) do not provide much detail despite seahorses being listed among the ten major marine fish groups exported from the country (Ekaratne, 2000). Similarly, fisheries studies in northwestern Sri Lanka report the occurrence and collection of seahorses for the marine aquarium trade (Dayaratne et al., 1995a; Dayaratne et al., 1995b) but do not provide details on catches, population status or distribution. The only studies of seahorses in Sri Lanka are limited to laboratory studies of growth parameters, survival rates and pathology under culture conditions (Ranasinghe et al., 2010; Ranasinghe \& Epa, 2010). Two species, $H$. fuscus and $H$. spinosissimus have been reported as occurring in Sri Lanka by Lourie et al. (2004) but the range and habitats are not well known. Neither of these species have been studied in the wild, and current knowledge is limited to aquarium studies and observation of specimens from fisheries (Vincent, 1994a; Vincent, 1994b; Vincent, 1995b; Morgan \& Panes, 2007). This paper presents the results of the first field studies on seahorses in Sri 
Lanka as well as the first field study on the distribution, density and population structure of $H$. fuscus and $H$. spinosissimus.

\section{Material and methods}

\section{Study Site}

The study was conducted in Puttalam Lagoon (7०45'- 8०25 N; $\left.79^{\circ} 42^{\prime}-79^{\circ} 50^{\prime} \mathrm{E}\right)$, a large tropical estuary system located in northwestern Sri Lanka (Figure1). This area experiences four seasons based on wind and rainfall patterns. The northeast monsoon from October to December; first inter-monsoon from January to March; southwest monsoon from April to June; and second inter-monsoon from July-September (Wallberg \& Johnstone, 1995). The lagoon is approximately $30 \mathrm{~km}$ in length from north to south, with a width ranging from $3-12 \mathrm{~km}$, and has a surface area of $226 \mathrm{~km}^{2}$ (Arulananthan et al., 1995; Wijeratne et al., 1995). It is connected to the Indian Ocean through a narrow strait at its northern boundary. The mean depth inside the lagoon is around $1.5 \mathrm{~m}$, with maximum depths of $6-7 \mathrm{~m}$ in two narrow channels at Kalpitiya (Perera \& Siriwardena, 1982). There are seasonal variations and spatial gradients in salinity with higher salinity during the drier months and in the southern end where hyper saline conditions may prevail during some parts of the year (Arulananthan et al., 1995). Average salinity is around 37 psu (Arulananthan et al., 1995), but varies between 35-60 psu in the south and 25- 40 psu in the north (Rydberg, 1991 in Wallberg \& Johnstone, 1995). Water temperature ranges from $27^{\circ}-29^{\circ} \mathrm{C}$ throughout the year (Wijeratne et al., 1995). Underwater visibility is typically less than $1 \mathrm{~m}$, but may reach 3 $\mathrm{m}$ in some areas during extended periods of calm weather. The lagoon has several important tropical wetland habitats such as mangroves, seagrass meadows and salt marshes (Dayaratne et al., 1995b). Seagrass communities are particularly well developed with Enhalus acoroides, Cymodocea serrulata and C. rotundata being the dominant species (Dahanayaka, 2009; Dahanayaka et al., 2010; Udagedara \& Kumara, 2014). 


\section{Seahorse Distribution}

Field surveys were carried out between January and December 2009 at seven sampling sites within the Puttalam Lagoon using the push net transect method (English et al., 1997) (Figure 1). Fisher interviews and catch inspections were used to obtain basic information about seahorse occurrence and assist with site selection. Sites were defined as the near shore area adjacent to the shore. Transects were located parallel to the shore, between 10 and $50 \mathrm{~m}$ from the shoreline, at depths ranging from approximately $0.5-1.5 \mathrm{~m}$. This depth was selected as the optimal for use of push net sampling. The location for the first transect was randomly selected. Thereafter transects were located at $20 \mathrm{~m}$ intervals from the first. Each site was sampled 4 times during the year in March, May, July and October, covering all major seasonal variations described by Wallberg $\&$ Johnstone (1995). Five transects were completed per site for each sampling session. At each site, a push net with a width of approximately 1 $\mathrm{m}$ was deployed by a local fisher along a $50 \mathrm{~m}$ transect (covering an area of $50 \mathrm{~m}^{2}$ ). The net was checked for seahorses at $10 \mathrm{~m}$ intervals and any seahorses found were retained in a plastic container. At the end of each transect morphological information for each seahorse was recorded and all seahorses released back into the water. 


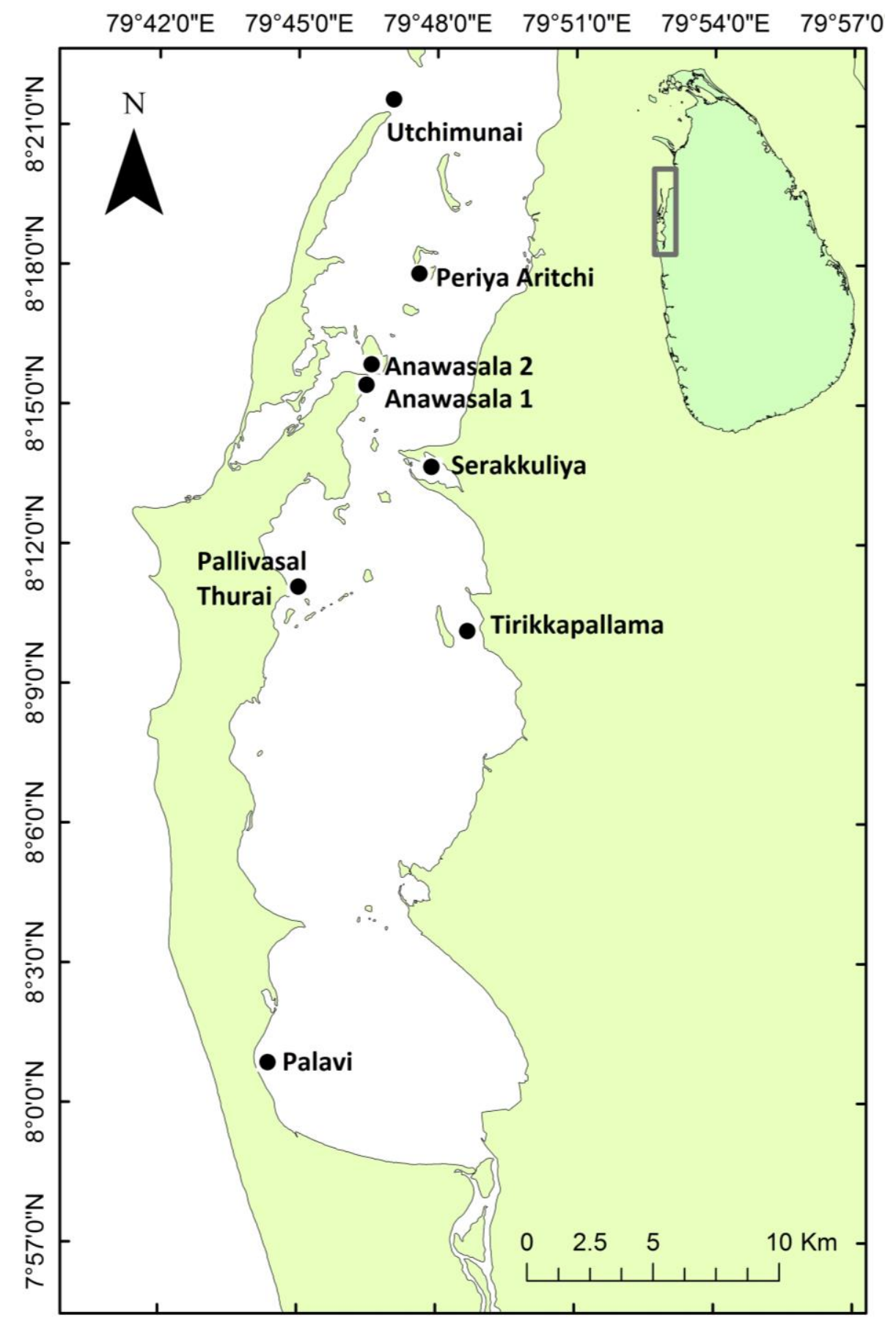

Figure 1. Map of Puttalam lagoon showing sampling locations 


\section{Substrate Surveys and Seagrass Distribution}

Fringing seagrass beds are found over extensive areas of the lagoon shore and the shoreline of islands. The species, abundance and percentage cover of seagrass was studied using 1 $\mathrm{m} \times 1 \mathrm{~m}$ quadrat samples along a $30 \mathrm{~m}$ transect at each sampling site. Triplicate samples were taken at $10 \mathrm{~m}$ intervals along the transect. Each site was sampled once a month for 12 months to document any seasonal variations. Species of seagrasses were identified using available keys (Abeywickrema \& Arulgnanam, 1991).

\section{Seahorse Population Information}

Seahorse species was identified according to Lourie et al. (2004). Seahorse body length was measured as height from the tip of the tail to the top of the coronet as described by Lourie et al. (2004) using a ruler with an accuracy of $1 \mathrm{~mm}$. Seahorses with a visible pouch were determined to be males and others were determined to be females similar to the methods used by Doh et al. (2006) and Foster \& Vincent (2004). Determining sexual maturity of seahorses in the field is complicated as accurate estimates require laboratory dissections which has practical and conservation implications (Foster \& Vincent, 2004). While the presence of a fully developed brood pouch in males may not always be an indicator of sexual maturity it is considered as a key index (Foster \& Vincent, 2004) and was used as an indicator of sexual maturity among male seahorses during the study.

Seahorses collected from around the sampling site of Anawasala by several local fishers were provided to an aquarium fish collection center in Kalpitiya. These seahorses are therefore representative of the local population of Puttalam Lagoon and population data was gathered during two visits to the collection center. Visits were carried out on an ad hoc basis based on presence of the owner. The species, sex and body length of 200 randomly sampled seahorses accounting for around three fourths of seahorses available during the visits were recorded. This was combined with data from transects to provide a larger sample size of seahorses from the lagoon. 


\section{Data Analysis}

The size of seahorses between species was compared using a Mann-Whitney test. A Kruskal Wallis test was used for multiple comparisons of size between sex within and between species and for comparing seahorse occurrence between sites. A Dunn's pairwise comparison was carried out to identify differing species and sex when the Kruskal Wallis test indicated a significant difference. The BIO-ENV function was used to relate seahorse presence to seagrass coverage and to determine seagrass species associated with any inter-site variability with seahorse occurrence (Clarke \& Warwick, 2001). Statistically significant values for Spearman rank Correlation Coefficient $(p<0.05)$ between the number of seahorse species per and seagrass species were calculated for each sampling site.

\section{Results}

\section{Habitat Structure}

Out of the seven genera of seagrasses recorded from Sri Lanka (Udagedara et al., 2017) six were found at all study sites except Palavi. The tropical eelgrass (Enhalus acoroides), serrated-tipped seagrass (Cymodocea serrulata), and round-tipped seagrass (Cymodocea rotundata) were the dominant species making up around $80 \%$ of the substrate within seagrass beds. The densities of the other three species were low and together comprise less than $20 \%$ of seagrass cover. C. serrulata was the most widespread species and was present in all transects except Palavi, mostly mixed with E. acoroides. It was also observed at depths of more than $2 \mathrm{~m}$. Results indicate that there is a patchy distribution of seagrasses throughout the study area (Table1). 
Table 1. Seagrass coverage at sampling sites

\begin{tabular}{|c|l|c|}
\hline Site & $\begin{array}{l}\text { Seagrass Species } \\
\text { Coverage }\end{array}$ & Salinity (ppm) \\
\hline Utchimunai & $\begin{array}{l}\text { Thalassia hemprichii 30\% } \\
\text { Cymodocea serrulata 10\% } \\
\text { Cymodocea rotundata 10\% } \\
\text { Halophila ovalis 10\% } \\
\text { Halodule uninervis 10\% } \\
\text { Enhalus acoroides 5\% }\end{array}$ & $30-50$ \\
\hline Periya Aritchi & $\begin{array}{l}\text { Enhalus acoroides 40\% } \\
\text { Cymodocea serrulata 10\% } \\
\text { Cymodocea rotundata 10\% } \\
\text { Thalassia hemprichii 10\% } \\
\text { Halophila ovalis 10\% } \\
\text { Halodule uninervis 10\% }\end{array}$ & $30-45$ \\
\hline Anawasala 1 & $\begin{array}{l}\text { Cymodocea serrulata 40\% } \\
\text { Enhalus acoroides 30\% } \\
\text { Cymodocea rotundata 20\% }\end{array}$ & $30-40$ \\
\hline Anawasala 2 & $\begin{array}{l}\text { Cymodocea serrulata 10\% } \\
\text { Enhalus acoroides 15\% } \\
\text { Cymodocea rotundata 5\% }\end{array}$ & $30-40$ \\
\hline Serakkuliya & $\begin{array}{l}\text { Cymodocea serrulata 40\% } \\
\text { Enhalus acoroides 40\% } \\
\text { Cymodocea rotundata 10\% }\end{array}$ & $30-40$ \\
\hline Tirikkapallama & Halodule uninervis 80\% & $30-55$ \\
\hline Palavi & Halophila decipiens 65\% & $30-60$ \\
\hline
\end{tabular}

\section{Seahorse distribution among sampling sites}

Two species of seahorses, $H$. fuscus and $H$. spinosissimus were recorded on transects with $H$. fuscus being significantly more abundant $(\mathrm{p}<0.05)$. Seahorses were recorded at five of the seven sites with no seahorses recorded at Palavi and Anawasala 2. H. fuscus was recorded at all five sites where seahorses were recorded while $H$. spinosissimus was not recorded at Anawasala and Utchimunai. The mean density of $H$. fuscus was $0.006 \mathrm{~m}^{-2}$ (SE 0.001 ) and the mean density of $H$. spinosissimus was 0.002 $\mathrm{m}^{-2}$ (SE 0.001). The combined mean density of all seahorses within the five sites where seahorses were present was $0.008 \mathrm{~m}^{-2}$ (SE 0.001). There was a greater occurrence of seahorses on 
transects during sampling in July (Kruskal-Wallis $\mathrm{p}=0.04$ ) compared to the other three samples (Figure 2).

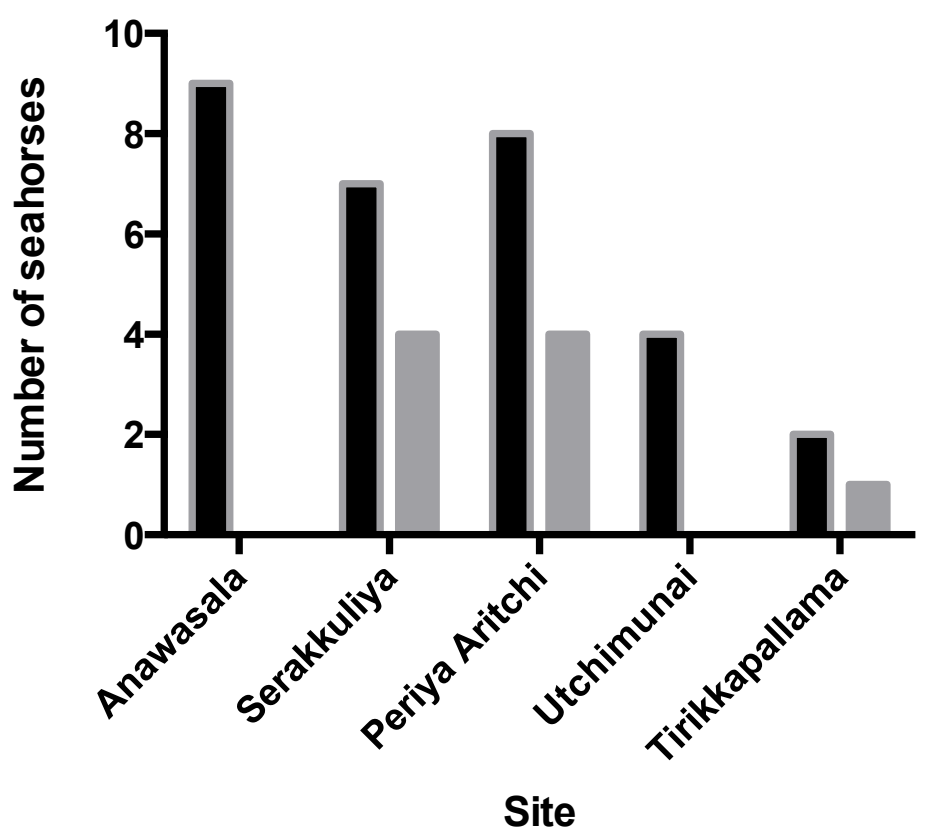

H. fuscus
H. spinosissimus

Figure 2. Total number of seahorses by species recorded at each site

Seahorses were significantly more abundant in areas with seagrass than in areas devoid of seagrass $(p<0.05)$. Two species of seagrass, namely Enhalus acoroides and Cymodocea serrulata appear to affect distribution of $H$. fuscus and $H$. spinosissimus with Spearman Rank Correlation Coefficients of 0.427 and 0.425 respectively.

\section{Size}

Hippocampus fuscus (mean $8.21 \mathrm{~cm}$; SE 0.08) was significantly larger (Mann-Whitney $\mathrm{p}<0.001$ ) than $H$. spinosissimus (mean $6.64 \mathrm{~cm}$; SE 0.17). Both male (mean $7.81 \mathrm{~cm}$; SE 0.09) and female (mean $8.53 \mathrm{~cm}$; SE 0.12) $H$. fuscus were significantly larger (Kruskal-Wallis $\mathrm{p}<0.001$; Dunn's Multiple Comparison 
$\mathrm{p}<0.05$ ) than male (mean $6.77 \mathrm{~cm}$; SE 0.17) and female (mean $6.56 \mathrm{~cm}$; SE 0.25) H. spinosissimus (Table 2). Within species, there was a significant difference in size between $H$. fuscus males and females (Mann-Whitney $\mathrm{p}<0.001$ ), but there was no such difference between sexes of $H$. spinosissimus (Mann-Whitney $\mathrm{p}=0.81$ ). Most $H$. fuscus were between $7 \mathrm{~cm}$ and $9 \mathrm{~cm}$ (min 5.5 $\mathrm{cm}$; $\max 12 \mathrm{~cm}$ ) (Figure 3) while most $H$. spinosissimus were between $6.5 \mathrm{~cm}$ and $7 \mathrm{~cm}(\min 3 \mathrm{~cm}$; $\max 9 \mathrm{~cm})$ (Fig. 4). The height of the smallest sexually mature male, or male with a fully developed brood pouch was $5.5 \mathrm{~cm}$ for $H$. fuscus and $6 \mathrm{~cm}$ for $H$. spinosissimus.

Table 2. Comparison of seahorse height (values in centimeters) ${ }^{*}$ and ${ }^{* *}$ Significantly different (Kruskal-Wallis $\mathrm{p}<0.05$ )

\begin{tabular}{|l|l|l|l|l|}
\hline Species & $\begin{array}{l}\text { Mean } \\
\text { Height } \\
\text { Male }\end{array}$ & $\begin{array}{l}\text { Mean } \\
\text { Height } \\
\text { Female }\end{array}$ & $\begin{array}{l}\text { Mean } \\
\text { Height } \\
\text { (SE) }\end{array}$ & $\begin{array}{l}\text { Size Range } \\
\text { in } \\
\text { Literature }\end{array}$ \\
\hline H. fuscus & 7.81 & $8.53^{*}$ & $8.21^{* *}$ & $8-12$ \\
H.spinosissimus & $(0.09)^{*}$ & $(0.12)$ & $(0.08)$ & $5.3-16$ \\
& 6.77 & 6.56 & $6.64^{* *}$ & \\
& $(0.17)$ & $(0.25)$ & $(0.17)$ & \\
\hline
\end{tabular}

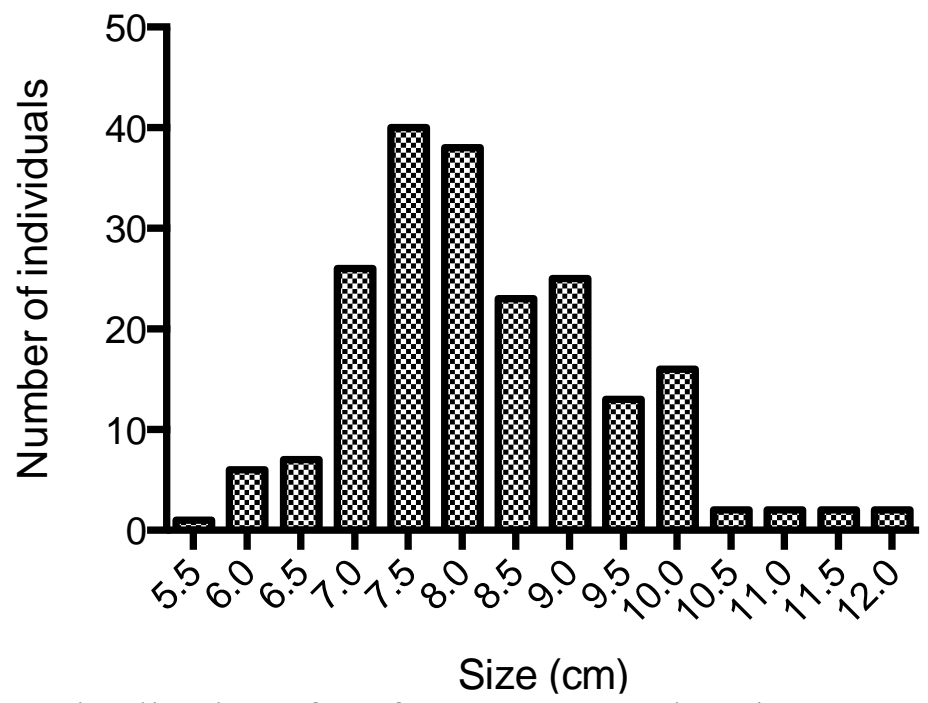

Figure 3. Distribution of $H$. fuscus among size classes 


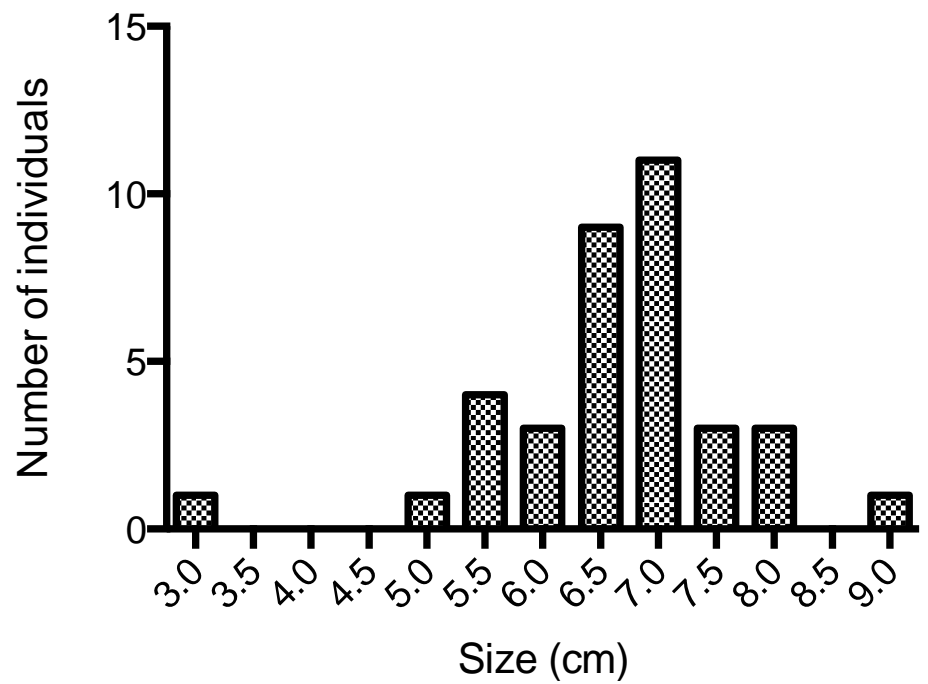

Figure 4. Distribution of $H$. spinosissimus among size classes

\section{Sex ratios}

A higher percentage of seahorses sampled through both push net surveys and at the collection center were females. $H$. fuscus showed a more even ratio of females vs. males with $55 \%$ of the animals sampled being females. However, for $H$. spinosissimus almost $64 \%$ of the animals sampled were females. Only 10 of the total 239 seahorses sampled appeared to be pregnant males with swollen brood pouches, and there was no noticeable seasonal pattern in the presence of pregnant animals. The mean size of pregnant males for $H$. fuscus was $8 \mathrm{~cm}(\mathrm{n}=9)$ and for $H$. spinosissimus $7 \mathrm{~cm}(\mathrm{n}=1)$.

\section{Discussion}

\section{Distribution patterns}

This study found two species of seahorse, H.fuscus and $H$. spinosissimus in the Puttalam Lagoon, Sri Lanka, a shallow, seagrass dominated habitat. Both species are known to occur in Sri Lanka (Lourie et al., 2004). H. fuscus was more common and occurred in more areas of the lagoon than $H$. spinosissimus. Seahorse distribution was correlated with the presence of seagrass, especially E. acoroides and C. serrulata. Seagrasses 
may increase prey density, capture efficiency and predator avoidance (Bell and Westoby, 1986; Flynn and Ritz, 1999) and are known as an important habitat for seahorses (Foster and Vincent, 2004; Vincent et al., 2011). H. fuscus has been reported from shallow protected bays with calm water, algal reefs and seagrass beds up to a maximum depth of $10 \mathrm{~m}$ (Lourie et al., 2004). In Sri Lanka, it is known to occur around the Jaffna Peninsula (Vincent, 1994a \& 1994b), an area with shallow lagoons and extensive seagrass habitats (Sivalingam, 2005). In contrast, $H$. spinosissimus has only been reported from marine waters with a benthic composition of sand, octocorals and sponges and in depths greater than $8 \mathrm{~m}$ (Morgan and Panes, 2007). Both $H$. fuscus and $H$. spinosissimus have previously not a been associated with estuaries, and only seven species of seahorse $(H$. abdominalis, $H$. capensis, $H$. hippocampus, $H$. kuda, $H$. mohnikei, $H$. reidi and $H$. whitei) are known to occur in estuaries (Lourie et al., 2004; Harasti et al., 2012).

Of the two sites where seahorses were not recorded Anawasala 2 had sparse seagrass cover and was composed mainly of open mud substrate. The other site Palavi did not have the seagrass species $C$. serrulata that was closely correlated with seahorse presence. It is also the southernmost sampling site and located in an area with high salinity variation (Arulananthan et al., 1995) that may result in unfavorable conditions for seahorses. Ex-situ studies have shown that juvenile seahorses were susceptible to high mortality when salinity increased or decreased more than $10 \mathrm{psu}$ and when salinity exceeded 50 psu (Hilomen-Garcia et al., 2003). It is likely that some seahorses may occur in the southern end of the lagoon and were not recorded in surveys considering the low densities encountered at all sites. However, interviews with fishers in the south of the lagoon indicated that seahorses are rare compared to fishers further north in the lagoon.

Estimates of seahorse density are influenced by site selection and survey methods, with randomly placed transects tending to report lower densities than focal grids (Foster and Vincent, 2004). Studies using randomly placed transects have reported densities of $0.007 \mathrm{~m}^{-2}$ (K. Martin-Smith unpublished data) and $0.008 \mathrm{~m}^{-2}$ (Bell et al., 2003) that are closer to results from Puttalam Lagoon. However, these surveys used the underwater 
visual census method. In a similar study using push net transects Masonjones et al. (2010) found densities of $0.08 \mathrm{~m}^{-2}$ for H. zosterae in Tampa Bay, Florida. Seahorse distribution can be patchy and is characterized by sparse densities in some areas compared to high densities in others (Masonjones et al., 2010; Harasti et al., 2012). Nonrandom, targeted sampling in areas known for higher abundance of a study species can lead to higher density estimates by intensively sampling such areas. During this study, sampling sites were selected to represent shallow sub-tidal habitats of Puttalam Lagoon and were not biased towards specific sites with high abundance of seahorses.

Although higher numbers of seahorses were recorded in July the small sample size preclude definitive conclusions. However, surveys of seahorse by-catch in three different fishing gear types including push nets in Puttalam Lagoon also show higher bycatch of seahorses around July. From end May to August the Puttalam Lagoon is subject to very strong winds and rough water conditions that causes physical disturbance to Seagrasses as is evident by uprooted seagrasses and torn blades along the shoreline. This may decrease the availability of suitable holdfasts (West \& Larkum, 1983) and possibly increase vulnerability of seahorses to fishing and push net sampling.

\section{Size}

The mean height of both species falls within the range for adults reported by Lourie et al., (2004), although the mean height of male $H$. fuscus in Puttalam Lagoon is less than the range of 8$12 \mathrm{~cm}$ reported by Lourie et al. (2004). However, the smallest males with well-developed brood pouches and therefore assumed to be sexually mature were smaller than that reported in the literature. $H$. fuscus is known to reach sexual maturity at $8 \mathrm{~cm}$ (Lourie et al., 2004), and $H$. spinosissimus at $9.8 \mathrm{~cm}$ (Morgan \& Panes, 2007). Given the limited information available for these two species it is possible that they reach sexual maturity at a smaller size than is currently reported. However, it is also extremely possible that the size of sexually mature males was underestimated. Foster \& Vincent (2004b) state that although it is commonly used in field studies, the presence of a fully developed brood pouch may not always be an accurate indicator of sexual maturity in male seahorses. Laboratory dissections are 
likely required to verify the size at sexual maturity for both males and females of $H$. fuscus and $H$. spinosissimus.

Other than for one $H$. spinosissimus measuring $3 \mathrm{~cm}$, seahorses smaller than $5 \mathrm{~cm}$ were not recorded. Like many seahorses $H$. spinosissimus has a planktonic stage soon after birth, and insitu surveys have revealed planktonic stage juveniles ranging from $6.52-23.8 \mathrm{~mm}$ (S. Morgan unpublished data). The juvenile stage of $H$. fuscus is not well understood, and although ex situ studies have inferred that it does not have a planktonic stage (Golani \& Fine, 2002) it is not clear if such observation apply in the wild. While juveniles may have been missed due to a planktonic stage it is unclear as to why seahorses between 3-5 $\mathrm{cm}$ were not recorded. Other fisheries studies also show that intervening size classes between small juveniles and adults of several marine fish including two species of seahorses $(H$. guttulatus and $H$. hippocampus) are rarely seen in benthic surveys and plankton tows (Pérez-Ruzafa et al., 2004; Curtis \& Vincent, 2005). While smaller seahorses may have been missed due to the sampling methodology they may be utilizing a different habitats has been observed in $H$. comes in the Philippines (Perante, 2002; Morgan \& Vincent, 2007).

\section{Sex Ratios and Reproduction}

Given the small sample size of $H$. spinosissimus it is possible that the higher numbers of females are due to some immature males without a developed brood pouch being recorded as females. However, it should also be noted that several of the smaller seahorses were in fact mature males and inn $H$. fuscus females were larger than males.

A major challenge to studying seahorses in Sri Lanka is low visibility. Coastal lagoons such as Puttalam appear to be the preferred habitat of seahorses in Sri Lanka. However, the extremely low visibility precludes carrying out underwater visual surveys. While push net surveys are a good substitute they have limitations in understanding ecology and space use. For example, information on holdfasts, behavior clustering cannot be determined with push net surveys. In addition, push net surveys 
may possibly record lower numbers as they depend on seahorses being collected in the net by chance.

\section{Conclusions}

The correlation of seahorse distribution with seagrass cover has major conservation implication in the Puttalam Lagoon, where overall seagrass cover is reported to be decreasing along with changes in community structure. Seahorses are also vulnerable to changes in physical conditions such as changes in salinity and there is also evidence that salinities may have increased over the last several decades (Arulananthan et al., 1995). These changes may decrease the area of suitable habitat and have potential impacts on population status.

Puttalam Lagoon is also subject to intense fishing pressure, and many fishing methods used in the lagoon have been attributed to the degradation of seagrass habitats (Dayaratne et al., 1995a). It was also observed that many of these methods result in by-catch that includes seahorses. As such, despite attempts to control the export trade of seahorses from Sri Lanka, wild populations may be exposed to significant threats due to indirect fishing and habitat degradation. The results of this study indicate that basic life history parameters for $H$. fuscus and $H$. spinosissimus may be more varied than reported in the literature. Both these species have not been studied in detail in the field and current knowledge is limited. This study while providing useful insights is limited in scope and geographical coverage. Further studies of distribution, habitat use and population structure for both $H$. fuscus and $H$. spinosissimus are needed to fully understand the ecology and population dynamics of these species as well as general seahorse distribution and ecology in Sri Lanka.

\section{Acknowledgements}

Fieldwork for this study was supported by the COMARIO Program, Linnaeus University Sweden, and the Zoological Society of London.

\section{References}

Abeywickrema, B.A., \& Arulgnanam, P. (1991). The marine angiosperms in Sri Lanka. MAB Publications 18. Natural 
Resources, Energy and Science Authority, Colombo, Sri Lanka.

Allen, G.R. (2008). Conservation hotspots of biodiversity and endemism for IndoPacific coral reef fishes. Aquatic Conservation: Marine and Freshwater Ecosystems. 18, 541-556.

Arulananthan, K., Rydgerg, L., Cederlöf, U., \& Wijeratne, E.M.S. (1995). Water Exchange in a Hypersaline Tropical Estuary, The Puttalam Lagoon, Sri Lanka. Ambio. 24, 438-443.

Baum, J.K. Meeuwig, J.J., \& Vincent, A.C.J. (2003). Bycatch of lined seahorses (Hippocampus erectus) in a Gulf of Mexico shrimp trawl fishery. Fishery Bulletin. 101, 721-731.

Baum, J.K., \& Vincent, A.C.J. (2005). Magnitude and inferred impacts of the seahorse trade in Latin America. Environmental Conservation. 32, 05-319.

Bell, J.D., \& Westoby, M. (1986). Variation in seagrass height and density over a wide spatial scale: effects on common fish and decapods. Journal of Experimental Marine Biology and Ecology. 104, 275-295.

Bell, E.M., Lockyear, J.F., \& Mcpherson, J.M. (2003). First field studies of an Endangered South African seahorse, Hippocampus capensis. Environmental Biology of Fishes. $67,35-46$.

Clarke, K. R., Warwick, \& R. M. (2001). Change in Marine Communities: An Approach to Statistical Analysis and Interpretation, 2nd ed. Plymouth: PRIMER-E.

Curtis, J., \& Vincent, A. (2005). Distribution of sympatric seahorse species along a gradient of habitat complexity in a seagrass-dominated community. Marine Ecology Progress Series. 291, 81-91.

Curtis, J.M.R., \& Vincent, A.C.J. (2008). Use of population viability analysis to evaluate CITES trade-management options for threatened marine fishes. Conservation Biology. 22, 1225-1232. 
Dahanayaka, D.D.G.L. (2009). A preliminary study on the distribution of sea grass communities and associated faunal diversity in the Puttalam lagoon, Sri Lanka, First National Symposium on Natural Resource Management, Department of Natural Resources, Sabaragamuwa University of Sri Lanka. $47 \mathrm{pp}$.

Dahanayaka, D.D.G.L., Wijeyaratne, M.J.S., Dassanayake, G., Warnajith, K.N.S., Tonooka, H., Minato, A., \& Ozawa, S. (2010). Spatial Distribution of Seagrass species and associated fauna in the Lagoon Environment: Case study in Puttalam Lagoon, Sri Lanka, Proceedings of the 6th International Student Conference at Ibaraki University. 168-169 pp.

Dayaratne, P., Gunaratne, A.B.A.K., \& Alwis, M.M. (1995a). Fish Resources and Fisheries in a Tropical Lagoon System in Sri Lanka. Ambio. 24, 402-410.

Dayaratne, P., Lindén, O., \& De SIlva, M.W.R. (1995b). Puttalam Lagoon and Mundel Lake, Sri Lanka: A Study of Coastal Resources, Their Utilization, Environmental Issues and Management Options. Ambio. 24, 391-401.

Doh, H., Gronkjaer, P., \& Simonsen, V. (2006). Otolith morphology, microstructure and ageing in the hedgehog seahorse, Hippocampus spinosissimus (Weber, 1913). Journal of Applied Ichthyology. 22, 153-159.

Ekaratne, S.U.K. (2000). A review of the status and trends of exported ornamental fish resources and their habitats in Sri Lanka FAO Bay of Bengal Programme, Chennai, India, $51 \mathrm{pp}$.

English, S., Wilkinson, C., \& Baker, V. (1997). Survey Manual for Tropical Marine Resources. Australian Institute of Marine Science, Townsville, Australia, 390 pp.

Felício, A.K.C., Rosa, I. L., Souto, A., \& Freitas, R. H. A. (2006). Feeding behavior of the longsnout seahorse Hippocampus reidi Ginsburg, 1933. Journal of Ethology. 24, 219-225. 
Flynn, A. J., \& Ritz, D. A. (1999). Effect of habitat complexity and predatory style on the capture success of fish feeding on aggregated prey. Journal of the Marine Biological Association of the United Kingdom. 79, 487-494.

Foster, S.J., \& Vincent, A.C.J. (2004). Life history and ecology of seahorses: implications for conservation and management. Journal of Fish Biology. 65, 1-61.

Giles, B.G., Si Ky T., Hoang, D. H., \& Vincent, A. C. J. (2006). The catch and trade of seahorses in Vietnam. Biodiversity and Conservation. 15, 2497-2513.

Golani, D., \& Fine, M. (2002). On the occurrence of Hippocampus fuscus in the eastern Mediterranean. Journal of Fish Biology. 60, 764-766.

Harasti, D., Martin-Smith, K., \& Gladstone, W. (2012). Population dynamics and life history of a geographically restricted seahorse, Hippocampus whitei. Journal of fish biology. 81, 1297-1314.

Hilomen-Garcia, G. V., Delos, R., \& Garcia, C.M.H. (2003). Tolerance of seahorse Hippocampus kuda (Bleeker) juveniles to various salinities. Journal of Applied Ichthyology. 19, 94-98.

IUCN (2010). IUCN Red List of Threatened Species. Available at http: / www.iucnredlist. org.

Kendrick, A.J., \& Hyndes, G. A. (2005). Variations in the dietary compositions of morphologically diverse syngnathid fishes. Environmental Biology of Fishes. 72, 415-427.

Lourie, S.A., Foster, S.J., Cooper, E.W.T., \& Vincent, A.C.J. (2004). A Guide to the Identification of Seahorses. Project Seahorse and TRAFFIC North America. Washington DC: University of British Columbia and World Wildlife Fund. 120pp. 
Martin-Smith, K.M., \& Vincent, A.C.J. (2006). Exploitation and trade of Australian seahorses, pipehorses, sea dragons and pipefishes (Family Syngnathidae). Oryx.40, 141-151.

Masonjones, H.D., Rose, E., McRae, L. B., \& Dixson, D. L. (2010). An examination of the population dynamics of syngnathid fishes within Tampa Bay, Florida, USA. Current Zoology. $56,18-133$.

McPherson, J.M., \& Vincent, A.C.J. (2004). Assessing East African trade in seahorse species as a basis for conservation under international controls. Aquatic Conservation: Marine and Freshwater Ecosystems. 14, 521-538.

Meeuwig, J. J., Hoang, D. H., Si Ky, T., Job, S. D., \& Vincent, A. C. J. (2006). Quantifying non-target seahorse fisheries in central Vietnam. Fisheries Research. 81, 149-157.

Morga, S.K., \& Panes, H.M. (2007). Threatened fishes of the world: Hippocampus spinosissimus Weber 1913 (Syngnathidae). Environmental Biology of Fishes, 82, 2122.

Morgan, S.K., \& Vincent, A. C. J. (2007). The ontogeny of habitat associations in the tropical tiger tail seahorse Hippocampus comes Cantor, 1850. Journal of Fish Biology. 71, 701-724.

O’Donnell, K.P., Pajaro, M.G., \& Vincent, A. C. J. (2010). How does the accuracy of fisher knowledge affect seahorse conservation status? Animal Conservation. 13, 526-533.

Perante, N. (2002). Biology of a seahorse species, Hippocampus comes in the central Philippines. Journal of Fish Biology. $60,821-837$.

Perera, W.K.T., \& Siriwardena, P.P.G.S.N. (1982). Topography of Puttalam Lagoon. Journal of Inland Fisheries, Sri Lanka. 1, 97-98. 
Pérez-Ruzafa, A., Quispe_Becerra, J. I., García-Charton, J. A., \& Marcos, C. (2004). Composition, structure and distribution of the ichthyoplankton in a Mediterranean coastal lagoon. Journal of Fish Biology. 64, 202-218.

Perry, A.L., Lunn, K.E., \& Vincent, A.C.J. (2010). Fisheries, large-scale trade, and conservation of seahorses in Malaysia and Thailand. Aquatic Conservation: Marine and Freshwater Ecosystems. 20, 464-475.

Ranasinghe, R., Epa, U.P.K., Chandaratne, N., \& Mallawaarachchi, M.A.J.C. (2010). A study on increasing larval survival of sea horse (Hippocampus kuda) under culture conditions. Proceedings of the $16^{\text {th }}$ Sessions of the Sri Lanka Association for Fisheries and Aquatic Resources, Colombo, 33 pp.

Ranasinghe, R., \& Epa, E.P.K. (2010). Breeding of the endangered seahorse, Hippocampus kuda and constraints for larval development under captivity. Proceedings of the $30^{\text {th }}$ Annual Sessions of the Institute of Biology, Sri Lanka, Colombo, 24 pp.

Rosa, I. L., Oliveira, T. P. R., Castro, A. L. C., de Souza, M. L. E., Xavier, J. H. A., Nottingham, M. C., Dias, T. L. P., BrutoCosta, L. V., Araújo, M. E., Birolo, A. B., Mai, A. C. G., \& Monteiro-Neto, C. (2007). Population characteristics, space use and habitat associations of the seahorse Hippocampus reidi (Teleostei: Syngnathidae). Neotropical Ichthyology. 5, 405-414.

Rydberg, L. (1991). Workshop on tropical coastal lagoon ecosystems. SAREC Documentation, pp. 78-85.

Salin, K.R., \& Yohannan, T.M. (2005). Fisheries and trade of seahorses, Hippocampus spp., in southern India. Fisheries Management and Ecology. 12, 269-273.

Sivalingam, S. (2005). General features and fisheries potential of Palk bay, Palk strait and its environs. Journal of the National Science Foundation, Sri Lanka. 33, 225-232. 
Udagedara, U.S.C., \& Kumara, P.B.T.P. (2014). present status of Seagrass ecosystems in the Puttalam lagoon, Sri Lanka, the 11th International Seagrass Biology Workshop, 6-10th November 2014, Sanya, China, 62 pp.

Udagedara, S., Fernando, D., Perera, N., Tanna, A., \& Bown, R. (2017), A first record of Halodule pinifolia Miki den Hartog, and new locality of nationally endangered Halophila beccarii Asch, from the eastern coast of Sri Lanka, International Journal of Aquatic Biology, 5, 328-335.

Vincent, A. C. J. (1995a). Trade in Seahorses for Traditional Chinese Medicines, Aquariums and Fishes Curios. TRAFFIC Bulletin. 15,125-128.

Vincent A.C.J. (1995b) A role for daily greetings in maintaining seahorse pair bonds. Animal Behaviour. 49, 258-260.

Vincent, A. C.J. (1994a). Operational Sex Ratios in Seahorses. Behaviour, 128, 153-167.

Vincent, A.C.J. (1994b). Seahorses Exhibit Conventional Sex Roles in Mating Competition, Despite Male Pregnancy. Behaviour. 128, 135-151.

Vincent, A.C.J., Foster, S.J., \& Koldewey, H.J. (2011). Conservation and management of seahorses and other Syngnathidae. Journal of Fish Biology. 78, 1681-724.

Wabnitz, C., Taylor, M., Green, E., \& Razak, T. (2003). From Ocean to Aquarium: The global trade in marine ornamental species, Cambridge, UK, $65 \mathrm{pp}$.

Wallberg, P., \& Johnstone, R. (1995). Diurnal Variations in Pelagic Bacterial and Primary Production During Monsoon and Intermonsoon Seasons: Puttalam Lagoon, Sri Lanka. Ambio. 24, 418-422.

West, R.J., \& Larkum, A.W.D. (1983). Seagrass primary production - a review. Proceedings of the Linnean Society of New South Wales. 106, 213- 233. 
Wijeratne, E.M.S., Cederlöf, U., Rydberg, L., \& Arulananthan, K. (1995). The Tidal Response of Putlalam Lagoon, Sri Lanka: A Large Shallow Tropical Lagoon. Ambio. 24, 444-447.

Wijesekara, R.G.S., \& Yakupitiyage, A. (2001). Ornamental fish industry in Sri Lanka: present status and future trends. Aquarium Sciences and Conservation. 3, 241-252.

Wilkinson, C. (2000). Status of the Coral Reefs of the World. Australian Institute of Marine Science, Townsville, Australia, $363 \mathrm{pp}$. 